\title{
"humanidades
}

Revista Humanidades

ISSN: 2215-3934

humanidades@ucr.ac.cr

Universidad de Costa Rica

Costa Rica

\section{Capitalismo de la seducción, exposición y emoción en la paulatina sociedad del 'me gusta'}

Briceño-Montilla, M.Sc. Luis Alfonso

Capitalismo de la seducción, exposición y emoción en la paulatina sociedad del 'me gusta'

Revista Humanidades, vol. 12, núm. 1, e49300, 2022

Universidad de Costa Rica, Costa Rica

Disponible en: https://www.redalyc. org/articulo. $0 a$ ? id=498068490013

DOl: https://doi.org/10.15517/h.v12i1.49300

\section{(c) (1) $\Theta$}

Esta obra está bajo una Licencia Creative Commons Atribución-NoComercial-SinDerivar 3.0 Internacional. 
Desde las ciencias exactas, la tecnología y el conocimiento

\section{Capitalismo de la seducción, exposición y emoción en la paulatina sociedad del 'me gusta'}

Capitalism of Seduction, Exposure and Emotion in the Gradual Like's Society

M.Sc. Luis Alfonso Briceño-Montilla

Universidad Nacional Experimental Rafael Maria Baralt

- Unermb, Trujillo, Venezuela

ciudadbohemia1@gmail.com

iD https://orcid.org/0000-0001-6713-1070
DOI: https://doi.org/10.15517/h.v12i1.49300

Redalyc: https://www.redalyc.org/articulo.oa? $\mathrm{id}=498068490013$

Recepción: 14 Octubre 2021

Aprobación: 17 Noviembre 2021

\section{Resumen:}

El capitalismo de la seducción, exposición y emoción, son una serie de analogías que involucran aspectos como la necesidad implícita de representación, similar a la dinámica consumista; nociones como autoexplotación, crisis de la representación, así como mecanismos y estrategias provenientes del campo de la psicología, son algunos de los elementos que se emparentan con actividades llevadas a cabo por las grandes tecnológicas (Facebook), como maniobras corporativistas de dominación en el universo de la red. Así, el objetivo del presente ensayo gira en torno a reflexionar crítica e interpretativamente sobre presupuestos como ideología de la necesidad, espectáculo, indignación, transparencia, atención, lenguaje emoji, “erotismo” como lucro, aceleración, circulación rauda de información, adicción y concentración de usuarios. La metodología implícita se situa el campo de la hermenéutica analógica, en aras de contribuir con un aporte teórico crítico de carácter social. En cuanto a las reflexiones finales, estas giran en torno a los memes como disrupción racional y lógica de circulación viral en consonancia con la alusión de sociedad del me gusta.

Palabras Clave: Tecnologías de la información, Ideología, Crisis cultural.

\section{Abstract:}

The capitalism of seduction, exposure and emotion are a series of analogies that involve aspects such as the implicit need for representation, similar to consumer dynamics; Notions such as self-exploitation, crisis of representation, as well as mechanisms and strategies from the field of psychology, are some of the elements that are related to activities carried out by large technology companies (Facebook), such as corporatist domination maneuvers in the universe. of the network. Thus, the objective of this essay revolves around critically and interpretively reflecting on assumptions such as ideology of need, spectacle, indignation, transparency, attention, emoji language, "eroticism" as profit, acceleration, rapid circulation of information, addiction and concentration of users. The implicit methodology is situated in the field of analogical hermeneutics, in order to contribute with a critical theoretical contribution of a social nature. As for the final reflections, these revolve around memes as a rational and logical disruption of viral circulation in line with the allusion of the like society.

KEYWORDS: Information technology, Ideology, Cultural crisis.

\section{INTRODUCCIÓN}

El capitalismo de la exposición en la paulatina sociedad del 'me gusta', es una analogía que implica elementos como la necesidad intrínseca de representación de individuos atravesados por deseos de exhibición en espacios virtuales. En primer lugar, tomaremos de Baudrillard (2009) el concepto de 'la génesis ideológica de las necesidades', noción ligada a interacciones sígnicas mediadas bajo la alusión Sujeto-Signo-Objeto. Este término se relacionada con la lógica capitalista consumista desde la perspectiva de mercancías consumibles. Consecuentemente, de $\operatorname{Han}(2014 ; 2013 \mathrm{a} ; 2013 \mathrm{~b}$ ), correlacionaremos y refinaremos parte de la naturaleza de exposición en el ciberespacio, a través de conceptos como 'crisis de la representación', 'enjambre digital', 'sociedad de la indignación y transparencia', como especies de patologías originadas por la autoexplotación y manipulación consumista perenne. 
En cuanto a la noción de capitalismo de la emoción y seducción, aspectos como la explotación de los estados anímicos, mecanismos de coacción y adicción, generados por las gigantes tecnológicas, fungen como elementos esenciales con la finalidad de crear codependencia tecnológica. Para Webb (2020) entre las grandes corporaciones se encuentran: por un lado, Google, Amazon, Apple, IBM, Microsoft y Facebook, ubicadas en Estados Unidos; por el otro, Baidu, Alibaba y Tencent de China.

En cuanto a la captación de atención, esta representa un factor determinante, por lo que Llaneza (2019) señala diversos elementos, entre los cuales tenemos: el botón del like. Esta herramienta, surgió como estrategia para consumir el máximo tiempo posible de atención de los usuarios en redes sociales, en este caso: Facebook. Además, refiere otros mecanismos similares a las industrias de los juegos de azar, para generar codependencia psicológica. Otro elemento, deriva de las notificaciones fantasmas, gracias a la reproducción de zumbidos del móvil como activadores neurales. Un reconocido psicólogo del comportamiento Eyal (2014) (citado en Llaneza 2019) afirma lo siguiente:

Todo comienza con un disparador, una acción, una recompensa y luego una inversión, y es a través de estos ciclos sucesivos, a través de estos ganchos donde se forman los hábitos (...) una vez que se forma un hábito, ya no son necesarios esos disparadores. Esos activadores externos (una notificación, un correo electrónico o cualquier tipo de timbre o llamada) (p. 106).

Asimismo, elementos como los memes, influencers (personalidades influyentes en el ámbito virtual), recopilación de datos, algoritmos, fake new, simbología emoji, concentración de plataformas virtuales y diversas actividades de interacción, configuran algunos de los mecanismos y estrategias en alineación con lo conceptualizado. Según Peirano (2019) "la industria aún no sabe cómo controlar las emociones, pero se ha especializado en detectar, magnificar o producir las que más beneficio generan: indignación, miedo, furia, distracción, soledad, competitividad, envidia" (p. 54). Por tanto, tales estrategias forman parte de la lógica de explotación en diversos espacios virtuales, para que las emociones o estados anímicos tributen likes y reacciones.

Además, surgen fenómenos como la desinformación mediática viral ciberespacial (fake new) y una especie de regresión, analfabetismo funcional y promoción del pensamiento mágico como principal fuente de energía, dispuesta desde distintos planos maniqueistas, motorizados por las redes sociales, memes y noticias falsas, como ya mencionamos. Para Romano (2009) el pensamiento mágico persiste bajo formas circundantes de la realidad y persiste, durante el proceso de generación de conocimiento. Es decir, cuando este se construye entre espacios vacíos (lagunas) en su intento por dar cognoscibilidad a la realidad.

Ante la fragmentación del conocimiento, se origina una especie de pérdida holística frente a tales estructuras. Por ello, la reproducción de microhistorias y los retazos de la 'realidad' son recreados por los medios de masas y espacios virtuales bajo el poder corporativo. De esta manera, surge el pensamiento mágico como compensación sustitutiva de lo real. Al mismo tiempo, se objetualiza lo mostrado como un todo, ahora deshuesado en escenas, planos, enfoques y contextos a conveniencia de los creadores de contenidos. Como en el caso de plataformas como Youtube y, en especial, las redes sociales. En palabras de Peirano (2019):

\footnotetext{
De todas las plataformas, YouTube ha sido la más propensa a las fake news y las teorías de la conspiración. Principalmente porque es un contenido muy rentable. La ficción es más lucrativa que las noticias reales, porque genera emociones. Las fake news están diseñadas para indignar (...) Durante al menos una semana durante 2012, Facebook hizo que cientos de miles de usuarios leyeran exclusivamente malas noticias, y que otros tantos usuarios tuvieran la misma experiencia, pero al revés: solo les llegaban buenas noticias (p. 46-47).
}

Tales mecanismos de producción de contenidos, se concatenan con una especie de retorno al pensamiento mágico. Ante la evolución del pensamiento humano racionalista se impone mediáticamente dicha tendencia mágica, capaz de estructurar pequeñas piezas de la realidad bajo procesos lógicos y rigurosos de corte psicológico publicitario; en síntesis, ingeniería social-virtual. No en vano, en la tradición humana, particularmente en la época del teocentrismo (Dios centro del universo), se ejerció una gran presión sobre las 
comunidades científicas e individuos que representaban un peligro para los cimientos dogmáticos del poder eclesiástico dominante, es desde allí donde se da forma al término. Por ejemplo, nociones como el deseo sexual representaban una especie de enfermedad; la risa, un elemento subversivo ante el dominio eclesiástico, constituyendo formas de irracionalidad sancionable.

\section{IDEOLOGÍA DE LA NECESIDAD}

El consumismo guarda una relación con nuestro sistema de representación simbólica, el cual se señala como un aspecto intrínseco (Baudrillard, 2009). Es decir, la necesidad de existir dentro del mundo como imagen (logos). Por tanto, extrapola su enfoque bajo la relación: objetos-intercambios-sujetos, constantemente signados por las interacciones de reproducción simbólica. Particularmente, tal perspectiva nos proporciona una mirada acorde para analizar el fenómeno (representación-logos) reproducido en el ciberespacio (Baudrillard, 1976). En este sentido:

\footnotetext{
Cada grupo o individuo, antes incluso de asegurar su supervivencia, siente la urgencia vital de tener que producirse como sentido en un sistema de cambios y de relaciones. Simultáneamente a la producción de bienes, existe la urgencia de producir significaciones, sentidos, de conseguir que el-uno-para-el otro exista antes de que uno y otro existan para sí (Baudrillard, 1976 , p. 54).
}

Tal lógica de reproducción sígnica, la podemos evidenciar en la dinámica constante de las redes sociales, mediante la prominencia de las imágenes y selfies (autorretratos). No obstante, se trata de un fenómeno natural del cual nos distanciamos en parte, debido al impacto que poseen los medios de masas y ciberespacio en cuanto a la inoculación mediática de carestías. Sin embargo, deducimos por analogía que parte de la ideología de la necesidad se funda bajo una lucha entre signos y reproducción del 'Yo' como logos (imagen), ligado con la dinámica de consumo.

Para Baudrillard (2009) "el consumo nunca será una lógica de lo lleno y del demasiado, sino una lógica de la carencia pues esta está ligada al sistema de producción y de manipulación de los significantes sociales que engendran esa insatisfacción crónica" (p. 44). Tal lógica de las carencias y escases extrapolada al universo de la red, es un fenómeno a la inversa. Es decir, circula excesivamente información y producción de significantes. En las producciones de significaciones, el propósito fundamental de los sujetos es captar mayores posibilidades de reconocimiento dentro de espacios de interacción virtual, incluso antes de que ambos existan para sí; por lo cual, subyace parte de la lógica del consumismo.

Dicho de otro modo, es la del sujeto objetualizado, mediático, sobredimensionado y sobreexpuesto. Se origina así, una relación dialógica entre: consumismo y representación. Por tanto, dicha lógica es extendida como espacio de reproducción en el plano de las relaciones de interacción virtual simbólica. En este sentido, figuras como los influencers perpetúan, concentran y amplían estrategias similares a los medios de masas tradicionales. Asimismo, individuos comunes refuerzan, a partir de crisis de la representación, la autoexplotación, las falencias, los miedos, las ansias, los deseos, los vacíos y las inoculaciones mediadas por similar reconocimiento que implica un modo de habitar y hacerse lugar en el mundo digital. En cuanto a las redes sociales, Soto (2017) apunta lo siguiente:

En lugar de responder a una necesidad, las redes sociales conectaron con miedos profundos del ser humano. Encontraron en estos miedos su gasolina (...) Pusieron la herramienta al alcance de todo el mundo, y la auténtica naturaleza humana, baqueteada por el pánico, la inseguridad y la soledad, la transformó en el vehículo que transmite más velozmente los sentimientos de ofensa e indignación (p. 92).

Además, en el ascendente 'capitalismo de plataformas' son renovadas estrategias mediáticas de marketing como, por ejemplo, la utilización de figuras públicas e influyentes, un mecanismo con la finalidad de comercializar mercancías o extender ideas, ilusiones y esperanzas en diversas direcciones. Para Srnicek (2018) el capitalismo de plataformas centra la extracción de datos como materias primas; estas, no son 
necesariamente conocimiento en sí, pero representan informaciones acerca de hechos y opiniones. Sin embargo, pueden implicar conocimiento, gracias a los procesos de triangulación. En síntesis, Srnicek (2018) señala que, dichas plataformas han refinado y redimensionado su esencia monopólica, lo cual genera modelos que se han expandido en toda la economía y en las corporaciones tecnológicas. Dichos modelos están basados en un mayor grado de distinción de la información y han optimizado los procesos de captación, predicción, marketing y comercio.

Según el conocido portal de la BBC (2019) diez youtubers de los más influyentes en el año 2019 recaudaron US $\$ 162$ millones entre todos. Mientras que en el portal de la revista Forbes, Bernal (2020) señala que "Kim Kardashian vendió 10 millones de dólares de su perfume en un día" (p.1). Esto nos proporciona una idea sobre el impacto de tales figuras en una sociedad condicionada por el poder de las imágenes, la millonaria maquinaria de la industria publicitaria y los medios tecnológicos como renovados espacios de entretenimiento, bajo el modelo económico de plataformas digitales.

También, la 'lucha simbólica' evidencia como la difusión de la fama de deportistas de élite, notables figuras del espectáculo y anónimos se convierten en virales, tan emergentes en la actualidad de la red, impuestos por las plataformas y usuarios bajo estereotipos. Entre algunos de ellos, tenemos: youtubers, trotamundos, estrellas porno, por tan solo mencionar algunos ejemplos. En consecuencia, fungen como catalizadores, oxigenantes y figuras que renuevan axiomas del capitalismo corporativista mediático de los medios de masas tradicionales.

Por otro lado, la dinámica de los cinco mil amigos de Facebook, no implica necesariamente una relación íntima de la experiencia de reconocimiento mutuo, tan solo es un lugar de representaciones en constante circulación y causalidad sígnica, algorítmica, predictiva o de búsquedas semiconscientes. Por tanto, se origina lo que Baudrillard dimensiona como objetos-intercambios-sujetos, pero en el caso de la red, la imagen funda una especie de relación objetual que interactúa y motoriza la relación de intercambio, sumada a otras formas de codificación en la que se imponen figuras dominantes. En este sentido, cuando aludimos un tipo de sociedad del me gusta es en cierto modo un producto derivado de las redes sociales que va generando adicción y codependencia tecnológica. En esta dinámica, la necesidad de estar constantemente interconectados y expuestos se vuelca sobre relaciones de aprobación y reconocimiento. Además, elementos como la autoexplotación, la transparencia, la representación y la autopublicidad fundada en la imagen fungen como su principal aliado.

En otro orden de ideas, redes sociales como Facebook han incrementado técnicas de control y elevado los niveles de censura y vetos. Tanto en la lucha sistemática corporativista-estatal librada en el ciberespacio, bots, algoritmos, recopilación de datos e inteligencia artificial (IA), han comenzado a controlar la emisión de dichas informaciones, lo que podríamos interpretar como un mecanismo que prioriza la escasez, para generar necesidad y control de bienes cognoscitivos.

En un reciente artículo del portal RT (2021) se señala la advertencia del antropólogo e historiador Yuval Harari, quien argumenta que la IA, los algoritmos y los datos proporcionados a las corporaciones podrían acabar refinando métodos de manipulación, control y hackeo de las mentes humanas. Por otro lado, estrategias algorítmicas detectan enlaces a partir del tráfico y flujo de descargas sobre comunidades de libreros digitales (bibliotecas virtuales) que actualmente comparten y distan de la lógica monopólica de las tradicionales concepciones editoriales en masa.

No obstante, algunos autores van más allá del concepto tradicional de censura de las sociedades democráticas y los medios de masas. En este sentido, Soto (2017) establece dos aspectos importantes: "La crisis de legitimidad de la prensa (...) y el influjo de las redes sociales" (p. 93). Sobre este último punto, ejemplifica el caso de Frisa, un texto infantil que, en resumen, causó revuelo y tendencia en Twitter (efecto del trending topic). Todo surge a partir del contenido de dicha obra que en manos de una niña de nueve años de edad es comentado a su hermana de 18 y posteriormente a sus padres. Tras el daño moral que supusieron algunos fragmentos del texto para unos padres escandalizados, sin ni siquiera haber sido leído por completo, se puso en marcha la viralización en modo denuncia y, aunque solo trajo como consecuencia unas disculpas 
por parte de la editorial Alfaguara, otros dos textos censurados en las escuelas de Virginia (Estado Unidos) no corrieron con la misma suerte. A este fenómeno se le refiere como poscensura, debido al efecto que ejercen las personas y las redes sociales como cultura de la denuncia y la viralización.

\subsection{LA SOCIEDAD EN LA ERA DEL ESPECTÁCULO}

La sociedad en la era del espectáculo es una de desnudamiento absoluto, al mismo tiempo emparentada con nociones desde la perspectiva en Han (2014): exposición, crisis de la representación y autoexplotación. Por tal razón, en la creciente era de la interconexión y manifestación del yo digital, los hechos más significativos o poco trascendentes cotidianos han borrado las fronteras entre la esfera de lo privado y público. Exhibir una cena romántica, la petición de mano de un chico a una chica o viceversa, la publicación de un libro, un pícnic con amigos, autorretratos con frases motivacionales y reflexivas del tipo "lo esencial es invisible ante los ojos" exaltando atributos sensuales, visitas a espacios naturales, lugares turísticos, museos, realización de cosplay (imitaciones o doblajes de personajes y voces), entre otras tantas representaciones, constituyen el pan diario del universo de las redes sociales.

En este sentido, la autoexplotación desde este punto de vista es un fenómeno reproducido en dichas redes; su canal, la imagen. Proyectar constantemente el espacio de lo privado se ha convertido casi en un imperativo global de los interconectados en la actualidad. De igual modo, las representaciones deben ser perfectas ante los ojos de internautas sedientos de una realidad sobredimensionada. Como resultado de eso, se pueden observar desde las publicaciones de las estrellas del espectáculo, las cuales son capaces de concentrar millones de reacciones en Instagram tras horas de su publicación, así como las declaraciones provocadoras del expresidente estadounidense Donald Trump, hasta las aventuras sexuales y etílicas de algún deportista de élite o un meme viral. Todos estos elementos componen algunos de los rasgos de la creciente sociedad interconectada que motoriza el espectáculo como renovado axioma.

Según Han (2013a) la sociedad de la exposición es la de la pornografía, en la cual cada sujeto se convierte en productor de su propia publicidad; entre algunas de las características que la definen está su valor de exposición, convirtiendo a los sujetos en mercancías expuestas, descubiertas, desvestidas, despojadas y vueltas hacia afuera. Un elemento resaltante en el ciberespacio proviene del autorretrato (selfie) como símbolo de exposición, exhibición y objetualización.

En este sentido, Perasso a través del portal de la BBC (2015) afirma bajo la expresión 'la locura de las selfies' que, durante el año 2014, 1,2 millones de autorretratos fueron tomados tan solo en el Reino Unido, según un informe de la Ofcom (regulador de comunicaciones del Reino Unido). Mientras que en el portal 'vive Usa', Avalos (2018) señala que para tal fecha, en el planeta se tomaron 93 millones de selfies en promedio diariamente. Semejantes cifras dimensionan una idea del creciente fenómeno de autoexposición. Para Han (2013a) se trata de un tipo de coacción intrínseca, por ello dice:

La coacción de la exposición conduce a la alienación del cuerpo mismo (...) Este se cosifica como un objeto de exposición al que hay que optimizar. No es posible habitar en él. Hay que exponerlo, y con ello explotarlo. Exposición es explotación. El imperativo de la exposición aniquila el habitar mismo. Si el mundo se convierte en un espacio de exposición, el habitar no es posible. El habitar cede el paso a la propaganda, que sirve para elevar el capital de la atención (p. 30).

Por tal razón, parte de la esencia del capitalismo de plataformas y redes sociales corroe, surgiendo así un constante bombardeo de selfies como patología conductual 'selfities'; es decir, deseo compulsivo obsesivo de tomar fotografías de sí mismos, para luego ser publicadas en diversos espacios virtuales y redes. Por lo que una especie de dinámica objetual y propagandística se vuelca hacia una externalidad constante. Transformando a la existencia en un eterno espectáculo reciclado y serializado bajo diversos modos, encuadres, poses y estereotipos mediante la imagen. En palabras de Debord (1995): 
El espectáculo se presenta a la vez como la sociedad misma, como una parte de la sociedad y como instrumento de unificación

(...) El espectáculo no es un conjunto de imágenes, sino una relación social entre personas mediatizadas por imágenes (...)

Es una visión del mundo que se ha objetivado (pp. 8-9).

Tras dividir al mundo en pequeñas celdas o parcelas de la realidad, recreamos incesantemente contextos sesgados por la dinámica objetual del espectáculo. Tanto los medios de masas como el ciberespacio divisan recreaciones ilusorias, embargados por los valores mediáticos del espectáculo. El espectáculo, a su vez, culmina imponiendo etiquetas heredadas de los medios de masas tradicionales. Asimismo, la red representa un lugar de infinitas posibilidades con respecto a la fama y popularidad. Nos encontramos con la posibilidad de viralizarnos, como una especie de nuevo indicador de prestigio. Para ello, solo es necesario que cualquier individuo posea un dispositivo telefónico y cohabite en algún nicho de redes sociales. El espectáculo se ha implantado a través de espacios, aplicaciones y canales para su materialización como Tik Tok, Triller, Likee, Funimate, Byte, Dubsmash, Firework, Snapchat, entre otras.

\subsection{CRISIS DE LA REPRESENTACIÓN COMO ELEMENTO REFORZADOR}

La crisis de la representación es un elemento reforzador en la que el espectáculo y exhibición forman parte de la dinámica de circulación rápida en espacios virtuales. Para Han (2014) "La fotografía conserva las huellas cuasi materiales del referente real (...) La fotografía no es el espacio de la ficción o manipulación, sino un espacio de la verdad" (p. 68). Cuando vincula a la fotografía dentro de un espacio de lo real y la verdad, lo hace bajo nociones que representaron su esencia originaria. En este sentido, la captación del momento es manifestada en el acto que funda la memoria y el instante que, en esencia, se pretende captar-preservar:

La verdad de la fotografía consiste en que su destino implica estar unida al referente, es decir, al objeto real de referencia, en que ella es la emanación del referente. La distingue el amor y la fidelidad a él. La fotografía no es el espacio de la ficción o manipulación, sino un espacio de la verdad (Barthes, 1990 citado en Han, 2014, p. 68).

Sin embargo, dicha amenaza sobre la verdad es transfigurada por la naturaleza de la fotografía digital, las redes sociales y las aplicaciones; lo cual, supone un cambio de paradigma relacionado con la crisis de la representación. Por lo que Han (2014) menciona: "La fotografía digital cuestiona radicalmente la verdad de la fotografía. Pone fin definitivamente al tiempo de la representación. Marca el final de lo real. En ella no está contenida ninguna indicación del referente real” (p. 69). Tal cambio, mecaniza una especie de serialización de la imagen sobredimensionada, gracias a las intervenciones aportadas por los filtros que las aplicaciones $(A p p s)$ proporcionan, con la capacidad de distorsionar lo real. Por tanto, la fotografía es reducida a un valor irreal y estético serializado.

\subsection{INDIGNACIÓN COMO ESTRATEGIA DE SEDUCCIÓN}

Las redes sociales se han convertido en espacios de lucha, expresión, indignación, denuncia, rabia, dolor, asombro, espectáculo, intercambio, comercialización, disfrute, entre otros elementos. Tales espacios, representan un puente que vehicula el tráfico de información, circulación, aceleración e interacción virtual. Por lo que, aspectos como la indignación motorizan la volatilidad como una especie de estampida generadora de reacciones en cadena y reúne un aluvión de interacciones, mediadas por la atención-captación. Para Han (2014):

La sociedad de la indignación es una sociedad del escándalo. Carece de firmeza, de actitud. La rebeldía, la histeria y la obstinación características de las olas de indignación no permiten ninguna comunicación discreta y objetiva, ningún diálogo, ningún discurso (...) La indignación digital (...) es un estado afectivo que no desarrolla ninguna fuerza poderosa de acción (p. 14). 
Opera la indignación en varios sentidos: concentra, genera reacciones efusivas y atomiza, lo cual podría traducirse como una especie de disruptor psíquico, capaz de producir subidones anímicos y luego pasividad postindignación, bajo mecanismos coactivos como la difusión de noticias falsas, provocadoras e irritables. En palabras de Amorós (2018) "En este hábitat germinan fantásticamente las fake news. A ellas les va de maravilla que todo vaya deprisa porque su objetivo es viralizarse antes de que alguien dé la alerta y destape el bulo" (p. 32). Por lo tanto, tales mecanismos son puestos en marcha para generar desencadenantes, basados en la aceleración, circulación, novedad y escándalo continuo, para producir la interactividad virtual.

\subsection{TRANSPARENCIA Y CIRCULACIÓN VIRTUAL ACELERADA}

Para Han (2013a) "La sociedad de la transparencia es un infierno de lo igual (...) El sistema social somete hoy todos sus procesos a una coacción de transparencia para hacerlos operacionales y acelerarlos" (p. 12). Dinámicas como la excesiva circulación de información, la exposición, el compartir en todo momento, navegar y engancharse, generan un amasijo de datos, utilizados por las corporaciones con propósitos comerciales, de vigilancia, manipulación y control. Prevalece constantemente el ruido, el bombardeo y la viralización. Desde notificaciones, noticias falsas, tendencias, figuras influyentes, entre otros elementos, mantienen anclados a los usuarios a sus pantallas como si fueran una especie de drogadictos. En palabras de $\operatorname{Han}(2013 a)$ :

La presión de la aceleración va de la mano del desmontaje de la negatividad. La comunicación alcanza su máxima velocidad allí donde lo igual responde a lo igual, cuando tiene lugar una reacción en cadena de lo igual. La negatividad de lo otro y de lo extraño, o la resistencia de lo otro, perturba y retarda la lisa comunicación de lo igual (pp. 12-13).

Se produce un modo de eliminación de lo distinto y negativo, cediendo paso a una lógica de positividad y efusividad de lo instantáneo. La comunicación pierde su esencia dialógica desde la diferencia y se diluye en espacio de la vacuidad. Por lo que, redes sociales, viralización y aceleración imponen una lógica comunicacional de lo raudo. Asimismo, Virilio (1996) suma un nuevo estado y dice: "La pasividad del hombre posmoderno exige un aumento de excitación" (p. 112). Se convierten así la excitación, la transparencia y la circulación de informaciones en mecanismos de optimización, recaudación y generación de datos, alineados con modelos y procesos analíticos cuantificables. Según Terranova (2017):

La mayoría de los usuarios habituales de Internet están sujetos al poder de algoritmos como el PageRank de Google (que clasifica los resultados de nuestras búsquedas) o el EdgeRank de Facebook (que automáticamente decide en qué orden recibimos las novedades en nuestro muro de noticias), sin mencionar los muchos otros algoritmos menos conocidos (Appinions, Klout, Hum-mingbird, pkc, Perlin Noise, Cinematch, kdp Select y muchos más) que modulan nuestra relación con los datos y con los dispositivos digitales (p. 92).

En este caso, el valor reside en los datos y su circulación. Similar a la producción, consumo y distribución en todo el universo de la red. En este sentido, la clasificación, sectorización y utilidad de los mismos, configura un importante elemento a favor de los Estados y corporaciones que controlan nichos y espacios de la red. Por tanto, progresan los mecanismos que fortalecen y amplían la lógica del capitalismo, en este caso de plataformas.

\subsection{LENGUAJE EMOJI COMO EXTENSIÓN LÓGICA DE LA ACELERACIÓN Y LA FUGACIDAD}

Los emojis son una especie de lenguaje de los estados anímicos, debido a su representación iconográfica va desde la espontaneidad de una manita con el pulgar hacia arriba en señal de aprobación, un corazón rojo, hasta una carita que simboliza rabia o asombro. En consonancia con ello, para Camps (2011) "El lenguaje de 
las emociones se ha impuesto (...) La vergüenza, la ira, el miedo, son sentimientos que nos sobrevienen y, o bien nos impiden actuar, o nos llevan a hacerlo de la forma equivocada e irracional" (p. 15). Lo que la autora define como sentimientos en nuestro caso es el reflejo de los estados anímicos encarnados en la simbología emoji, impuesta desde el sector corporativista de las grandes tecnológicas y sus sistemas de mensajerías en diferentes redes sociales. Por analogía, el lenguaje emoji se emparenta con una especie de lógica enunciada anteriormente como circulación, aceleración, viralidad y fugacidad.

Tal estrategia, guarda una relación con un tipo de simplificación práctica y rauda. Su esencia reduccionista, simple y puntual, encajona los estados anímicos, impidiendo expresar con palabras nuestro rico universo interior, manifestado en diversas formas, incluyendo el lenguaje poético. En este sentido, dicha simbología, podríamos traducir como un tipo de empobrecimiento cognitivo y semántico. Para Romano (2017):

A través de la comunicación, del intercambio de informaciones, los seres humanos toman conciencia de sus experiencias, que contrastan con otros al expresarlas. La primera toma de conciencia se efectúa en el pronunciamiento del mundo (...) El lenguaje le da forma al mundo. La palabra es el primer ejercicio del poder (pp. 7-8).

Si nos apegamos a la definición descrita, es evidente que el lenguaje emoji solo comunica estados anímicos, su operacionalización es limitada, no genera un vínculo racionalista (sentimental), solo recursivo e instantáneo. Por extensión, la toma de conciencia se diluye bajo la espontaneidad serial, encarnada en las diferentes representaciones iconográficas. Por ello, las formas discursivas que exterioriza el uso de los emoticones son limitadas. En cuanto al poder que sustenta la maquinaria reproductora de dicho lenguaje, existe todo un despliegue que representa un negocio lucrativo.

La marca Emoji (2021) desde su portal electrónico apunta algunas características que la componen. Entre algunas de ellas están: en primer lugar, el marketing y publicidad; en segundo lugar, una de las bibliotecas más extensas del mundo; y, en tercer lugar, asesorías para web corporativas. Posee más de 25000 íconos y es, una marca registrada. Asimismo, se encuentra entre los 150 principales licenciantes mundiales, en el puesto número 57. En consecuencia, es un mega negocio que ha establecido más de 1000 licenciatarios notables a nivel global, gracias a su profunda efectividad y 'colectivismo'. Por otro lado, para Romano (2017):

La intoxicación lingüística tiene sus causas políticas y económicas (...) El uso manipulador del lenguaje es tan antiguo como el dominio de unos seres humanos sobre otros (...) El lenguaje, como el terrorismo, va dirigido a los civiles y genera miedo, ejerce violencia simbólica o psicológica (...) Las palabras son como minúsculas dosis de veneno que pueden tragarse sin darse uno cuenta (pp. 8-13).

Si bien, el lenguaje emoji posee unas características particulares, lo definido como dosis de veneno, va en el orden de un modo de minimalismo expresado y condensado en cada uno de los íconos. Mientras que, el lenguaje como terrorismo, violencia simbólica y psicológica proviene del despliegue e incorporación comunicativa producto de los dispositivos inteligentes que las grandes empresas corporativistas tecnológicas imponen en sus diferentes modos y estrategias.

\subsection{ADICCIÓN Y ME GUSTA COMO ESTRATEGIAS CORPORATIVISTAS DE DOMINACIÓN}

Progresivamente, observamos múltiples formas de captación de la atención en las comunidades y redes virtuales. Compartir, subir historias o autorretratos, aseguran una especie de presencialidad virtual. Tal intersubjetividad permanente, reproduce un modo de autoexplotación, la cual es recompensada por las reacciones entre los usuarios. El incremento publicitario de sí mismos, comporta una lucha diaria para posicionar y sostener una ilusión recreativa de vida perfecta, contenida en esos encuadres, colores, formas y polisemias. Diversas estrategias y mecanismos son desarrollados a través de modelos y aplicaciones desde el seno de las grandes tecnológicas (Google, Amazon, Apple, IBM, Microsoft y Facebook, Baidu, Alibaba y Tencent). En este sentido, desde el campo de la psicología conductual, tres elementos configuran modelos 
de captación desplegados en distintos reservorios o nichos digitales. En este sentido, B.J. Fogg menciona lo siguiente:

Para implantar un hábito de manera efectiva, tienen que ocurrir tres cosas al mismo tiempo: motivación, habilidad y señal. El sujeto tiene que querer hacerlo, tiene que poder hacerlo y tiene que haber algo en su camino que le impulse a hacerlo. Este último se llama trigger (desencadenante, activador o señal). Si falta cualquiera de las tres, la rutina no cuaja (...) Para que la fórmula funcione, la motivación y la habilidad tienen que ser más grandes que la frustración (citado en Peirano, 2019, p. 26).

La finalidad de generar adicción por medio de tecnologías inteligentes y redes sociales tiende la mascarada y artilugios a favor de los beneficios lucrativos que representan. De esta manera, funcionan como señuelos, con fines particulares, usualmente de corte económico y vigilancia. Si bien, estos pueden incorporar medios al servicio de la salud, modelos de ciudades inteligentes, cartografías digitales, entre otros, para generar un impacto positivo; en el fondo, encarnan una trama maquiavélica. Sin embargo, son sus verdaderos usos en el plano corporativo y estatal los que refuerzan su naturaleza invasiva. En cuanto a las redes sociales:

Según el Centro de Comprensión Retrospectiva de la Universidad de Duke, no recibir nunca notificaciones agrava el miedo a quedarse atrás. Entonces recibes la notificación y desbloqueas la pantalla del móvil, donde encuentras tu recompensa en likes, mensajes de otros, comentarios y otros paquetitos de dopamina que te hacen sentir mejor, te tranquilizan o que te lanzan a tuitear algo súper ingenioso (Peirano, 2019, p. 32).

Las emociones o estados anímicos, constituyen un objetivo esencial en aras de una constante explotación. Generar adicción y codependencia tecnológica se traduce literalmente en millones de dólares. Esto nos hace reflexionar sobre la naturaleza comunicativa manipulada como una de sus principales estrategias y activos. Asimismo, Peirano (2019) señala: "Saben que volverás antes si cada vez que subes una foto recibes automáticamente un like (...) LinkedIn explotaba este factor con un ícono donde se podía ver el tamaño de la red de cada usuario" (p. 32). La manipulación de los estados anímicos es el santo grial, capaz de generar subidones, bajones y adhesión.

Para Llaneza (2019) "Las redes sociales están llenas de recompensas impredecibles que captan de manera permanente, la atención de sus usuarios, creando en ellas una rutina que les obliga a revisar sus pantallas de forma habitual" (p. 109). Esta sensación de obligación sucede debido a dichos desencadenantes latentes como modo de recompensa. Parte de los cimientos de este fenómeno, se encuentran fundamentados bajo la teoría psicológica conductista desarrollada por Skinner (caja de Skinner) y posteriormente retomada y adaptada por B.J Fogg. Según Peirano (2019), la fórmula precisa que estableció: 'Psicología + economía + neurología + estadística + computación $=\$ \$ \$$, potenciada a través de los dispositivos tecnológicos, la web y las redes sociales. De esta manera, se entreteje una gran cadena destinada a la programación social, lucro, control y persuasión.

En consecuencia, Peirano (2019) apunta a que la motivación social se encuentra estrechamente relacionada con nuestra necesidad de ser aceptados en el mundo, la búsqueda de un lugar dentro de las comunidades humanas. Por tanto, tales motivadores son herramientas poderosas, debido a que la búsqueda de aceptación en las diversas comunidades virtuales se vuelve clave para la 'supervivencia'. Finalmente, Peirano (2019) afirma que Facebook posee el poder para motivar e influir en los internautas, gracias al elemento motivador. Las manifestaciones van desde colgar fotografías hasta escribir en sus muros, por lo que el deseo de aceptación social en los usuarios se encuentra signado en gran parte por la necesidad de representación.

\subsection{CONCENTRACIÓN DE USUARIOS Y "EROTISMO" COMO LUCRO}

Según Berardi (2003) "En la segunda mitad de los años noventa se desarrolló una auténtica lucha de clases en el seno del circuito productivo de las altas tecnologías. El devenir de la red ha estado marcado por esa lucha" (p. 13). Del mencionado circuito se pasó a la creciente disputa en la red, lo cual constituye un juego de alianzas, transferidas hacia un nuevo plano, el de pequeños inversionistas (cada vez más desplazados), 
grandes capitales, autoempleados, emprendedores, los cuales disputan tales espacios, con la posibilidad de ser aplastados por la maquinaria corporativista y estatal.

El lucro genera luchas entre diversos sectores del poder, en cuanto a la atención e importancia de las informaciones (datos) en espacios virtuales, con la finalidad de ser transformados en capital y otros beneficios como modelos algorítmicos, datos de suma importancia, entre otros. Su impacto es tal que, podemos evidenciar la trascendencia que representa. Un reciente ejemplo de ello, lo podemos señalar a través del creador de Wikileaks, Julián Assange, el cual ha sido encarcelado por develar información valiosa que atenta contra intereses de monopolios, políticos y sectores del poder dominante. Debido a su ejercicio de periodismo científico, como respuesta a la hegemonía comunicacional, tales revelaciones constituyen una clara señal del poder que posee el universo de la red y la necesidad de sectores hegemónicos por regularlo. Por otro lado, en cuanto al lucro que representa el uso de plataformas virtuales, Illouz (2007) señala:

En el contexto general de la economía de Internet, los sitios de citas y la publicidad online son grandes fuentes de dinero (...) De hecho, para el tercer trimestre de 2002, los sitios de citas se convirtieron en la principal categoría de contenidos pagos online con ganancias de más de 300 millones de dólares anuales (p. 165).

Es de suponer que tras la pandemia causada por la COVID-19 se haya dado un exponencial aumento de las cifras. Se modela así un renovado capitalismo de plataformas virtuales que concentra su poder según la capacidad para captar usuarios. Por ello, no solo el lucro interviene como principal estrategia, se genera nuevamente una dinámica de exposición y recopilación de datos como axiomas que operan bajo dicha dinámica. En torno a lo "erótico", se genera un millonario negocio, en el cual las carencias, el deseo, las inquietudes y los fetiches motorizan las actividades de interacción virtual. En este mismo orden de ideas, para Hakim (2012):

En el capital erótico se aúnan la belleza, el atractivo sexual, la vitalidad, el saber vestirse bien, el encanto, el don de gentes y la competencia sexual (...) El «capital erótico» es el cuarto activo personal, un activo al que hasta ahora no se hacía caso, aunque la vida cotidiana esté llena de recordatorios sobre su importancia (p. 14).

Además de la belleza y el atractivo sexual, los cuales aplican en el universo de la red, el capital erótico en el sentido de la virtualidad, produce un efecto de la externalidad, proyección, subasta y rasgos comunes. Es decir, confluyen todas las formas y estereotipos de belleza. Tal referencia, se alinea a un modo de ampliación mucho mayor gracias a las posibilidades de conexión que proporciona la web, el anonimato, la manipulación fotogénica, entre otros aspectos. Por tal razón, la captación de dichos activos es un importante elemento dentro del capitalismo de plataformas, junto con la ampliación de estándares de belleza e intereses específicos.

En palabras de Moreno (2016) "En nuestra sociedad, el capital erótico resulta central en todos aquellos espacios donde se funden la vida pública y la privada y donde el cuerpo se convierte en el centro de la interacción profesional" (p. 59). En nuestro caso, la sociedad de la interacción virtual es un nuevo espacio de confluencia social. Esta zona produce un cotejo similar y diversifica la aparición de nuevos fenómenos, con mayor alcance debido a la capacidad para desterritorializar el espacio físico. Así, se eliminan las fronteras y las barreras culturales. Tanto así que las posibilidades que brinda la red anulan nociones como el tiempo y ámbito laboral, ya que la propia oficina no limita las posibilidades de interacción, gracias la interconexión en tiempo real con el mundo virtual.

Asimismo, surgen otros fenómenos como el de plataformas que extrapolan actividades de un modo de prostitución, en este caso, orientadas bajo la dinámica exhibicionista. Para Zerega (2020) la plataforma virtual Only Fans se ha convertido en una opción lucrativa viable en América Latina, gracias al impacto de la pandemia COVID-19. Tal espacio, permite obtener ingresos sin la necesidad de vender el cuerpo. Sin embargo, se produce un tipo de fetichización u objetualización fundada en la imagen. Por lo que, la esencia de tal plataforma se centra en el contenido fotográfico y audiovisual sexual para adultos.

Según Motterle (2020) (citado en Zerega 2020): "la razón económica es el 90\% de lo que impulsa a una mujer a entrar en el trabajo sexual y la crisis económica amplifica este fenómeno” (p. 1). De modo que, 
podemos evidenciar otra cara del capitalismo erótico y la creciente presencia de plataformas como dinámica expansiva desde distintos frentes y modelos de negocios. En cuanto a la construcción de los sujetos, Illouz (2007) afirma:

El yo se construye descomponiéndolo en categorías discretas de gustos, opinión, personalidad y temperamento (...) el acto de subir un perfil a la web hace que Internet, al igual que otras formas culturales psicológicas como los talk shows y los grupos de apoyo, convierta el yo privado en una representación pública (...) Internet contribuye a una textualización de la subjetividad (...) es decir, a un modo de autoaprehensión en el que el yo se externaliza y objetiva a través de medios visuales de representación y lenguaje (pp. 169-170).

Bajo dicha lógica, podemos correlacionar tales elementos a nociones como la sociedad del espectáculo, exposición y objetualización en cierto modo. En la primera categoría, podemos evidenciar estrategias inherentes a la recolección de datos y mercadotecnia; para lo segundo, la triangulación de lo anterior genera un cruce preferencial común como el caso de las redes sociales; por último, similares conexiones surgen entre perfiles basados en dichos procesos, como resultado del aporte de datos proporcionados por los usuarios.

En cuanto a las formas culturales lógicas y la industria del entrenamiento mediático, grupos de apoyos y estructuras que congregan las posibilidades de encuentros concertados o casuales en el plano romántico y sexual, más espacios de la TV de Telecorazones transfiguran y extrapolan al 'Yo' privado, ahora publico gracias a los perfiles en la red. Sin embargo, existe la posibilidad en la web de preservar cierto grado de anonimato a partir de la falsificación de datos. Mientras que la objetivación se produce en la imagen y el lenguaje, en este caso.

\section{REFLEXIONES FINALES:CIBERJUNGLA Y MEMES COMO DISRUPCIÓN RACIONAL EN LA CRECIENTE SOCIEDAD INTERCONECTADA}

Para cimentar la composición de 'ciberjungla' en el universo de la red, es preciso referirnos a especies de ciberesferas, las cuales se asimilan a múltiples celdas digitales, compartimentos, similares a los ecosistemas, en este caso, extrapoladas a la red. Es decir, de la jungla como ese espacio donde coexisten diversas especies de animales pasamos al ciberespacio, el cual es habitado por una variedad de elementos como la IA, bots y algoritmos, los cuales coexisten imperceptiblemente con el resto de usuarios en la red. Dichas ciberesferas, posibilitan la fragmentación generada en espacios como el de las redes sociales, en las que los algoritmos dictan desde las noticias que leemos hasta las amistades, gustos y preferencias.

En cuanto a la definición del término meme, este es originado desde el campo de la biología. Su base constituye un estudio con la relación genética (genes replicadores) y su capacidad para adaptarse, evolucionar, mimetizarse y perpetuarse a sí mismos. En este sentido, procesos biológicos constituyen la esencia del meme como idea contagiosa; si lo extrapolamos al ámbito de la cultura, significa la reproducción de imágenes, símbolos, palabras e ideas que buscan mutar, sobrevivir y perpetuarse. Dicho de otro modo, desde el campo de la genética:

$\mathrm{Al}$ igual que los genes se propagan en un acervo génico al saltar de un cuerpo a otro mediante los espermatozoides o los óvulos, así los memes se propagan en el acervo de memes al saltar de un cerebro a otro (Dawkins, 1994, citado en Rodríguez, 2013, p. 12).

Por tal razón, los memes se encuentran vinculados con la sociedad del me gusta porque aglutinan y generan reacciones en cadena gracias a su capacidad contagiosa como ideas nocivas y a su vez adictivas desencadenantes. Prosigue Rodríguez (2013) y dice: "los memes son tan egoístas como los genes. No tienen por qué ser necesariamente buenos, ni bellos, ni útiles, ni verdad. Lo único que hacen es extenderse y sobrevivir" (p. 12). Asimismo, surgen diversas estrategias de supervivencia como las de agrupaciones, combinación y resignificación, las cuales transforman sus contenidos y originan un mecanismo de supervivencia denominado memeplex (fusiones de memes). En este sentido, Blackmore (2000) sostiene que: 
El término «egoísta» en este caso significa que los genes actúan por sí solos y que el único interés que les motiva es la autorreplicación: solamente quieren pasar a la generación siguiente. Los genes, por supuesto, no «quieren» ni «tienen intereses» de la misma forma que las personas; los genes solo son instrucciones químicas capaces de ser copiadas (p. 32).

Tal autorreplicación en términos meméticos (memeplex) son producidos y reproducidos por los individuos bajo diversas formas estéticas y discursivas, puenteados por canales y medios de difusión, en los cuales la carga viral es la que determina su supervivencia o extinción. La viralidad es un fenómeno contagioso que progresa, un término bastante conocido y difundido en la web. En el presente, referencias como noticia viral, meme viral, lenguaje viral, virus informático, entre otras connotaciones, son expresiones comunes y casi naturales dentro de las comunidades virtuales. Consecuentemente, dicho fenómeno, posee características beneficiosas como también alberga un potencial peligro, por lo que su nivel de toxicidad puede repercutir como un oleaje en cadena, gracias al tráfico de información y posibilidades de alcance global que la red dota.

Para los aspectos positivos, tenemos ejemplos como: una noticia favorable para la recolecta de una obra benéfica, denuncias hacia algún agresor de animales, el nacimiento de un nuevo disco, entre otros. Sin embargo, la viralidad de la fake new (noticia falsa), distorsión de una idea, suicidio online, falsas acusaciones, pueden generar un impacto negativo y tangible de múltiples dimensiones.

Según Rodríguez (2013) "Muchos memes son letales cuando los cerebros se alimentan de ellos. El extremo es el memeoide, la persona cuyo comportamiento está totalmente dirigido por un meme” (p. 15). Por tal razón, la circulación viral y explosiva de combinaciones de ideas fanáticas, terroristas, religiosas y suicidas, abundan y generan un aluvión de estados anímicos, hechos violentos y sugestiones sobre los individuos condicionados por tales ideas, podrían ser desplegadas en parte relacionada con los memes y con mayor probabilidad en las fake new.

Para Rodríguez (2013) los individuos protegen y defienden memes como si representaran un lazo íntimo consigo mismos, mientras estos programan las ideas y pensamientos con los que articulan y dan forma a la realidad. Como consecuencia de ello, estos subordinan a la capacidad comprensora, lógica racional, afectando procesos para dar solución a una gran cantidad de problemas simples y complejos. Un meme puede convertirse en un fenómeno viral. Recientemente, según el portal Clarín (2021) Elías Navarro, un chico de 12 años de edad, pasó a ser reconocido en todo el continente de América, tras la grabación de un video chistoso en el que simula una transacción comercial en un local de la cadena Oxxo. La situación es recreada de manera un tanto pícara: tras la petición de artículos como por ejemplo preservativo, se origina una risa contagiosa (meme) por parte del adolescente.

Tras la difusión por medio de una página viral en el presente año (2021), a mediados de marzo se propagó la grabación y alcanzó veinticuatro millones de reproducciones. Esto le generó una censura inmediata por parte de la empresa, pero luego fue aprovechada por la cadena de comida Burger King como estrategia de mercadeo y publicidad de bajo costo y alto impacto. Así, lo que inició como una broma, rápidamente se tradujo en alta facturación lucrativa. Además de la fama y la estampida de memes, con respecto a un chico totalmente desconocido.

Tales ideas, las podemos equiparar bajo distintos planos interpretativos y de conjugación, que van desde las más absurdas, instauradas en el imaginario social, hasta otras de corte popular, explosivas, útiles, efímeras, jocosas, contradictorias, impopulares, peligrosas. Todas ellas, en modo reproductivo y mimético, buscando así, su final supervivencia.

Finalmente, son muchos los beneficios que aporta el universo de la red, el uso de la IA y modelos algorítmicos que no reflejamos en el presente ensayo. No obstante, los impactos, peligros, violaciones a la privacidad de datos, adicciones y otros aspectos, son importantes para la toma consciencia a partir de programas de formación, educación, regulaciones jurídicas y promoción de una cultura digital responsable, pues son muchas las tentaciones que ofrecen tales espacios. Diseñar y proponer modelos de plataformas virtuales seguras a través de la intervención estatal permitiría mayores grados de seguridad en cuanto a fenómenos como la ciberdelincuencia, robo de identidad, estafas y nuevas formas de delinquir. 
En cuanto a la adicción, producto de estrategias para el condicionamiento psíquico y conductual, es trascendental desde el plano ético y moral establecer una revisión a corporaciones y sus actividades en diversos contextos. Esto, debido a que muchos de los fenómenos emergentes son relativamente nuevos, queda mucho por hacer y establecer en pro de los intereses de la ciudadanía, para una especie de retorno en el que la figura del Estado se distancie de la complicidad con las corporaciones tecnológicas como el caso de la vigilancia llevada a cabo por naciones y entes gubernamentales de las tres actuales potencias globales (China, Rusia, EE. UU).

\section{REFERENCIAS BIBLIOGRÁFICAS}

Amorós, M. (2018). Fake news, La verdad de las noticias falsas. Plataforma Editorial.

Avalos, A. (2018, Junio). ¿Por qué tomarse selfies es bueno para la salud? Vive Usa. https://www.viveusa.mx/bienesta r/por-que-tomarte-selfies-es-bueno-para-la-salud

Baudrillard, J. (1976). La génesis ideológica de las necesidades. Editorial Anagrama.

Baudrillard, J. (2009). La sociedad de consumo: sus mitos, sus estructuras. Siglo XXI de España Editores S.A.

BBC New World (2019, diciembre). Los 10 youtubers con más ingresos de 2019 (y quién es el niño de 8 años que encabeza la lista). BBC News Mundo. https://www.bbc.com/mundo/noticias-50859909

Berardi, F. (2003). La fábrica de la infelicidad. Nuevas formas de trabajo y movimiento global. Traficantes de Sueños.

Bernal, C. (2020, marzo). Los 10 influenciadores de Instragram que más ganan en Colombia. Forbes Colombia. https ://forbes.co/2020/03/06/negocios/los-10-influenciadores-de-instagram-que-mas-ganan-en-colombia-2/

Blackmore, S. (2000). La máquina de los memes. Ediciones Paidós Ibérica S.A.

Camps, V. (2011). El gobierno de las emociones. Herder Editorial.

Clarín. (2021, abril). El niño Oxxo, la historia del chico de 12 años que se convirtió en una estrella internacional por un video viral. Clarin. https://www.clarin.com/viste/-nino-oxxo-historia-chico-12-anos-convirtio-estrella-inte rnacional-video-viral_0_-s7SLYUGl.html

Debord, G. (1995). La sociedad del espectáculo. Ediciones Naufragio.

Emoji The Iconic Brand. (2021). We are emoji - The Iconic Brand. Emoji The Iconic Brand. https://www.emoji.com /es/

Han, B. (2013a). La sociedad de la transparencia. Editorial Herder S.L.

Han, B. (2013b). La sociedad del cansancio. Editorial Herder S.L.

Han, B. (2014). En el enjambre. Herder Editorial S.L.

Hakim, C. (2012). Capitalismo erótico. Penguin Random House Grupo Editorial.

Illouz, E. (2007). Intimidades congeladas. Las emociones en el capitalismo. Katz Editores.

Llaneza, P. (2019). Data nomics Todos los datos personales que das sin darte cuenta y todo lo que las empresas hacen con ellos claves, consejos y herramientas para proteger tu privacidad. Editorial Planeta S.A.

Moreno, J. (2016). La cara oscura del capital erótico. Ediciones Akal, S. A.

Peirano, M. (2019). El enemigo conoce el sistema. Manipulación de ideas, personas e influencias después de la economía de la atención. Penguin Random House Grupo Editorial.

Perasso, V. (2015, agosto). La locura de los selfies en números. BBC News Mundo. https://www.bbc.com/mundo/no ticias/2015/08/150807_finde_selfies_estadisticas_lb

Rodríguez, D. (2013). Memecracia los virales que nos gobiernan como las ideas contagiosas usan internet para manipular tu mente. Centro Libros PAPF, S. L. U.

Romano, V. (2009). La formación de la mentalidad sumisa. Ministerio del Poder Popular para la Comunicación y Formación.

Romano, V. (2017). La intoxicación lingüistica. El uso perverso de la lengua. Fundación Editorial El perro y la rana. 
RT. (2021, octubre). Un antropólogo israelí advierte sobre el 'hackeo' a los humanos con IA: La vigilancia llegará por debajo de nuestra piel. $R T$. https://actualidad.rt.com/actualidad/408857-yuval-harari-hackeo-humanos-vigila ncia

Soto, J. (2017). Arden las redes. La poscensura y el nuevo mundo virtual. Editor digital: Titivillus.

Srnicek, N. (2018). Capitalismo de plataformas. Caja Negra Editora.

Terranova, T. (2017). Acelaracionismo Estrategias para una transición hacia el capitalismo. Caja Negra Editora.

Virilio, P. (1996). El arte del motor aceleración y realidad virtual. Manantial.

Webb, A. (2020). Nueve gigantes: Las maquinas inteligentes y su impacto en el rumbo de la humanidad. Paidós Empresa.

Zerega, G. (2020, diciembre). Only Fans acerca la prostitución a miles de jovenes en america latina. El Pais. https://elpais.com/mexico/sociedad/2020-12-05/only-fans-acerca-la-prostitucion-a-miles-de-jovenes-enamerica-latina.html 